\title{
The Relative Electoral Impact of Central Party Co-ordination and Size of Party Membership at Constituency Level
}

\author{
Justin Fisher (Brunel University), David Denver (Lancaster University) \& Gordon Hands \\ (Lancaster University)
}

\author{
Contact: \\ Justin Fisher \\ Department of Politics \\ Brunel University \\ Uxbridge \\ Middlesex \\ UB8 3PH
}

Email: justin.fisher@brunel.ac.uk 


\section{The Relative Electoral Impact of Central Party Co-ordination and Size of Party Membership at Constituency Level ${ }^{1}$}

Over the past decade, clear evidence has been produced showing that effective constituency campaigning in British general elections can lead to better electoral performance. This evidence has challenged the received wisdom that only national campaigning is significant and that efforts at local level are meaningless rituals. Denver et al have focused on the role of the national parties in strengthening local campaigns in target seats; Seyd \& Whiteley, by contrast, have stressed the importance of local party membership. This article attempts to assess the relative electoral impact of national party co-ordination and constituency party membership and suggests that the impact of these two factors varies by party.

\section{Introduction}

Over the past decade, the role and impact of constituency campaigning in British general elections have been fundamentally re-assessed. Three different teams of researchers (for brevity referred to as: Seyd \& Whiteley; Johnston \& Pattie; Denver \& Hands), using three different methodologies, have arrived at broadly similar conclusions - effective local campaigning, in most cases, leads to a better electoral performance. These results have not only confirmed previous findings in the United States (see, for example: Crotty, 1971; Jacobson, 1980, 1990) but have also challenged what was previously the received wisdom put forward, for example, by various 'Nuffield' studies - that only national campaigning is significant and that efforts at local level are meaningless rituals - and what was once a 'revisionist' position has now come to be widely accepted. That said, there have been differences between the three teams, not only in methodology but also in their conclusions about whether local campaigning 'works' for all of the major parties. Originally at least, both Seyd \& Whiteley and Johnston \& Pattie argued that the constituency campaigns of all three parties had a significant impact (see, for example Whiteley \& Seyd, 1994; Pattie, Johnston, et al., 1995). Denver \& Hands (1997, 1998, 2002) on the other hand, have suggested that constituency campaigning by the Conservatives has been notably less 
effective than campaigning by Labour or the Liberal Democrats: their analyses show no discernible effect of Conservative constituency campaigning in 1992 and 1997 and, at best, a small effect in 2001 .

A more significant disagreement has concerned which aspects of constituency campaigning are more important in affecting election outcomes. To a large extent, Seyd \& Whiteley's work on campaigning has been a by-product of their groundbreaking studies of party membership and they have used an index of membership activism in constituencies to demonstrate the effectiveness of local campaigns. Perhaps partly for this reason, they have stressed the importance of party membership. As they make clear, their index of activism - which is their measure of campaign intensity - scores more highly the more constituency members a party has: 'a given constituency party could obtain a high intensity score either by having a large number of members who are moderately active, or by having a few members who are highly active' (Whiteley and Seyd, 2003, p. 310). In contrast, Denver \& Hands have assigned an increasingly important role to the activities of central professional party staff in co-ordinating constituency campaigns as a whole, focusing resources on key constituencies and modernising campaign organisation at the local level. Of course, both the size of party memberships and increased influence from the centre are likely to be of significance: good campaigns cannot be run without a substantial voluntary input from members on the ground and the substantially greater resources available to the central party organisations clearly give them the potential to have a major impact on local campaigning. In this article, however, we seek to make some assessment of their relative significance: which makes the greater contribution to improved electoral performance at the constituency level? 
In general, the various components of campaigning are closely related, and disaggregating their effects is not an easy matter. However the nature of the data collected by Denver \& Hands at the general elections of 1992, 1997 and 2001, on the basis of surveys of election agents and organisers, allows us to construct measures of the extent to which the national party organisations have sought to exercise central involvement in different constituencies, as well as providing reliable estimates of constituency party memberships. ${ }^{1}$ Furthermore, it is clear that these two components of campaigning are not directly related. We present more evidence on this below, but there is no reason to believe that the constituencies that the national parties seek to target will have high levels of party membership or vice versa. Thus we should be able to provide some assessment of the relative importance of central party influence and local membership using fairly standard statistical techniques. It is necessary first of all, however, to say rather more about the influence of the central party organisations and how we propose to measure it.

\section{Developing a measure of central party influence}

We have a straightforward measure of constituency party membership. In all three surveys conducted by Denver and Hands, election agents were asked to give an estimate of their local membership at the time of the election - something that they were normally in a good position to be able to do. Comparisons with estimates of membership from other sources suggest that these data are reliable (Fisher, 2000). As a further test of reliability, levels of membership recorded in 1997 were correlated with those recorded in 2001 (this test could only be conducted for the period 1997 to 2001, as a boundary change after the 1992 election meant that any comparisons 
would be subject to inaccuracies). The correlation coefficients for the Conservatives, Labour and the Liberal Democrats were $0.812,0.823$ and 0.890 respectively. This further test suggests that the estimates of local party membership did not vary a great deal over time and so can reasonably be regarded as being reliable.

Developing a measure of central party influence or involvement is somewhat more difficult, however. Denver et al (2003) argue, on the basis of qualitative interviews, that all of the main parties have increased the extent of central involvement in local campaigns over the past decade. Before the 1990s, the contribution of party headquarters was mainly confined to offering training and advice to party workers, and providing routine 'servicing' - making campaign materials available for purchase, for example. Nonetheless, party organisers never entirely subscribed to the view that local campaigns were irrelevant. They were well aware that winning marginal seats was crucial to their chances of winning general elections and some attempts were made to improve campaigns in these seats by providing extra help with election literature, financial assistance, and so on. What has emerged over the past ten years, however, is a new and much stronger relationship between the national and local campaigns. National party professionals now seek to exercise much greater control over local campaigning by managing key constituency campaigns in crucial respects and integrating them much more closely into the national effort. They develop local campaign strategies and build them in as an integral part of the party's overall national campaign; they appoint special organisers (or provide centrally-paid agents in the case of the Conservatives) in target constituencies and in other ways seek to encourage the development of effective 
campaigning at the local level; they organise direct mail and telephone canvassing from outside the constituency; and so on. These changes began first, and have gone furthest, in the Labour party, but both the Conservatives and, to a lesser extent, the Liberal Democrats, have followed Labour's lead. As has been argued elsewhere, in many respects the initiative in local campaigning in target seats has passed from the local party to the national party headquarters (Denver et al 1998).

As suggested above, some of the questions asked by Denver \& Hands allow us to develop a quantitative measure of the extent of central involvement in local campaigns. It has to be said straight away that this measure is far from perfect. For example, there are no questions which might indicate the extent to which local campaigns were integrated into the parties' national campaigns or provide details of the activities of regional and national officials in the constituencies in the interelection period. Nonetheless, there are questions which provide a good indication of the extent and variation of central involvement in constituencies. These deal with:

- the amount of contact by national and regional offices with local organisers in the period before the campaign and during the campaign itself;

- whether a special organiser was appointed by party headquarters to work on the local campaign; and

- whether election software supplied by the party's headquarters was used in the constituency.

All of these questions were asked in each of the 1992, 1997 and 2001 surveys. In the 1997 and 2001 surveys, questions were added on the length of time before the 
election that a special organiser had been appointed and on whether there was telephone canvassing organised from outside the constituency.

We have used responses to these questions to construct two indexes of central involvement in local campaigns. The first, calculated for each party in each of the three elections separately, uses the questions asked in all three surveys (we label this the 'old' index); the second, again calculated separately for each election, covers 1997 and 2001 and uses the additional questions asked in the corresponding surveys (the 'new' index) - details of response categories can be found in the endnotes. ${ }^{2}$ The indexes were calculated as the (standardised) scores for each constituency on the basis of a Principal Components Analysis. ${ }^{3}$ For ease of presentation the scores have been adjusted to give a mean of 100 and a standard deviation of 33.3: campaigns having scores greater than 100 had higher than average central involvement, scores lower than 100 indicate lower than average central involvement. ${ }^{4}$ We have restricted analysis to English constituencies, excluding Scotland and Wales because a number of the relevant survey questions involved refer to 'national' contacts or 'party headquarters' and when asked in Scotland and Wales such questions are bound to be somewhat ambiguous. Respondents in these countries might easily think of their headquarters in Edinburgh, Glasgow and Cardiff, rather than London, as 'national'. Nationalist respondents, of course, would be certain to do so, not having 'regional' organisations equivalent to those of the other parties. 


\section{Are we measuring different things?}

Before attempting to assess the impact of central involvement and local membership on electoral performance, we first need to explore the relationship between our two variables and make sure that they are not simply replicating the more complete index of local campaign intensity used in previous analyses (Denver et al, 2003). In other words, we need to make sure that we are not using apparently different variables to measure overall campaign intensity. To form a judgement about this, we begin by correlating the measures of central involvement and local membership with the full campaign index for each party in each election. The results are shown in Table 1. As would be expected, there are positive and significant correlations between the full index and our other measures in every case. It is clear, however, that the relationships are far from perfect - although Liberal Democrat membership levels do correlate very strongly with the full campaign index. It is also worth noting that as expected, the correlations between the centralisation indexes and membership (not shown) are either weak or non-significant, with the exception of the Liberal Democrats, where the relationship is somewhat stronger, though never higher than 0.3

\section{[Table 1 About Here]}

A second way of describing the relationship between the three variables is to regress the index of central involvement and local membership levels against the full campaign index. The results are shown in Table 2. In order to produce coefficients for the independent variables which can easily be compared with each other, natural logarithms of the centralisation index and membership were used. This allows for 
intuitive percentage 'rate of change' comparisons to be made. These suggest that the relative impact of membership level and central involvement on the production of a strong campaign varies by party. First, in each election, the impact of Labour's central involvement is greater than is the case for the other parties. That is also true of Labour members (though the impact of Liberal Democrat members in 2001 is only marginally smaller). Secondly, whilst for both the Conservatives and Labour, members appear to have had a stronger impact on the intensity of campaigns in 1992, by 1997 and 2001, the reverse was true - centralisation appears to have had a greater impact. By way of contrast, members have a consistently stronger impact for the Liberal Democrats. Nevertheless, the main conclusion that we wish to draw at this stage is that on the basis of these two tests we can be reasonably sure that neither the index of central involvement nor the size of party membership is simply another way of measuring campaign intensity. They do not replicate the full index of constituency campaign strength.

\section{[Table 2 About Here]}

\section{The Development of Central Involvement}

A further preliminary question that is worth exploring is the extent to which changes in the quantitative indicator of central involvement in constituency campaigning corroborate the qualitative evidence outlined above. To describe change over time we have recalculated the original indexes taking all respondents in all the relevant elections together (i.e. pooling the data). We do this because the separate election indexes are based on standardised scores and thus are not strictly comparable across elections. On this basis, Table 3 compares the mean scores for central involvement 
for each of the three parties over all three elections using both the old and the new indexes. The data generally confirm the argument advanced on the basis of qualitative data. Firstly, the scores suggest that Labour took the lead in trying to manage constituency campaigns from the centre. In both 1992 and 1997 (and on both indexes in the latter case) Labour scores are well above the average and clearly higher than those for the other parties. Secondly, the Conservatives appear to have learned the appropriate lessons by 2001 - their scores on both indexes rose significantly and were, indeed, slightly larger than Labour's. Thirdly, although there is evidence of increasing central involvement on the part of Liberal Democrat headquarters, it is at a much lower level than is the case with the other parties. This is not surprising since although the degree of central involvement exercised from Liberal Democrat headquarters has grown, the party simply lacks the resources to do very much more than encourage constituency campaigners from the centre.

\section{[Table 3 About Here]}

We would expect, however, that central involvement would be greatest in key seats rather than in those safely held or unlikely to be won. As with the overall measure of campaign intensity, what matters is whether the resources and effort are distributed effectively across different types of seat - i.e. with most resources concentrated on target seats. Previous studies (Denver \& Hands, 1997) have shown, for example, that although the Conservatives had very strong constituency campaigns overall in 1992, their strongest campaigns were in their safest seats. Of course, parties only have limited control over how intense the campaigns are in particular constituencies membership levels, for example, often reflect previous electoral success (Fisher, 
2000; Fisher et al, 2006). In theory at least, they have much greater control over the targeting of their involvement in local campaigns. The data in Table 4 show the extent to which the parties have been effective in this respect.

In almost every case the central involvement index scores are clearly higher in target seats than in the other categories, suggesting that central co-ordinating efforts have been successfully focused on the campaigns that matter. The single exception is the Liberal Democrats in 2001 (on both the old and new index). However, this was the only occasion on which there were enough safely held Liberal Democrat seats to form a separate category. Even although these appeared safe 'on paper', most had been originally won by intense campaigning and the party's headquarters clearly maintained a strong interest in the progress of the campaigns in them.

In one sense, of course, all of this might be considered something of a tautology since the 'centre' decides which seats are target ones, it is likely that such seats will receive most central attention. And, as we have seen, this is largely so. However, what we are interested in is not just whether target seats receive most central attention, but also the relative difference between seats. As we can see, this varies quite considerably. For both Labour and the Liberal Democrats the extent to which central co-ordination was focused on target seats in particular increased sharply in 1997. The figure for Labour campaigns in target seats on the new index (160) is especially striking and compares with below average figures in the other categories. This is an indicator of the success of 'Operation Victory', the party's overall campaign strategy. For both parties, however, targeting, although still apparent, was less striking in 2001. In the case of Labour the decline in 2001 may reflect the 
greater inclusiveness of the party's targeting strategy in that election (Denver et al, 2002), but for both parties it also seems likely to reflect the changed political context: both had many more seats to defend following their successes in 1997 and, as a result, a significantly larger number of seats were targeted. Labour, for example, had 148 targets as compared with 90 in 1997. It is almost inevitable in these circumstances that centrally managed targeting of resources will be less effective. The figures suggest, however, that the Conservatives have steadily improved their effectiveness over the three elections - in spite of the fact that they also had many more targets in 2001 (180 compared with 100 in 1997) - which confirms our earlier suggestion that they have learned lessons and have, to a significant extent, 'caught up' with Labour.

\section{[Table 4 About Here]}

For the sake of comparison, we show in Table 5 the distribution of party members between target and non-target seats. There is not a lot that parties can do centrally to affect these figures, which are more likely to be a product of local contexts, but the data enable us to indicate the extent to which party members are distributed 'efficiently', so to speak. The evidence here suggests that both Labour and the Liberal Democrat campaigning may have benefited by having relatively large memberships in their target seats. Perhaps the most striking thing about the figures for the Conservatives is the sharp fall in membership over the period, but even in 2001 they had, on average, almost double the number of members in safe seats that they had in their targets. The figures also suggest that the Liberal Democrats may struggle to make further breakthroughs in what are currently non-target seats. The 
analysis presented in Table 2 showed that strong Liberal Democrat campaigns are heavily dependent on high membership levels, yet the party's mean membership level in 'not held not target' seats is relatively small.

\section{[Table 5 About Here]}

\section{The Electoral Impact}

We now return to the central concern of this article - the relative electoral impact of central party involvement and party membership. We return to the original index scores and use straightforward methods to explore this question, starting with simple bivariate correlations. We have argued elsewhere that the most suitable measure of party performance in this context is change in share of the electorate won between two elections (Denver et al, 2002;2003). However, because of boundary changes it is not possible to calculate change in share of the electorate figures for 1997, and we also report, therefore, analyses based on change in share of the vote in the three elections.

\section{[Table 6 About Here]}

The correlation coefficients reported in Table 6 suggest that Conservative attempts at central co-ordination have had singularly little impact on their electoral performance. None of the coefficients with the index of central involvement are statistically significant. Furthermore, where the coefficients for local party membership are significant the signs are in the wrong direction: higher memberships (found in the safest seats, of course) are associated with poorer performances. In contrast, in both 
1992 and 1997 Labour's electoral performance was positively and significantly correlated with the extent of central involvement and also with membership levels. In 2001, however, central involvement had no significant impact and larger memberships were associated with significantly worse performances. Central involvement on the part of the Liberal Democrats is associated with better performances in 1997 and 2001, as is membership in 1992 and 1997. In 2001, however, larger memberships were associated with larger declines in the share of the electorate obtained.

\section{[Table 7 About Here]}

The most economical and widely used ${ }^{5}$ way to control for the socio-economic composition of constituencies is to use share of the vote or electorate at the relevant election as the dependent variable (rather than change in share) and share of the vote or electorate at the previous election as a control variable. This effectively controls for a range of socio-economic variables associated with variations in party support across constituencies. Table 7 reports partial correlations on this basis. As can be seen, the relationships between the central involvement index and Conservative performance remain non-significant. In the case of the Liberal Democrats, the coefficients are generally somewhat stronger than in Table 6 and, in particular, the relationships between performance and both independent variables are now positive and significant. For Labour, all measures now suggest that central involvement had a positive impact on performance in 2001. On the other hand, the relationships between membership and performance in 2001 remain negative. 
Finally, in Table 8 we introduce into the analysis two additional control variables which are likely to affect party performance but which are not captured by share of the vote or electorate at the previous election: region and personal incumbency. ${ }^{6}$ The dependent variables are share of the electorate in 1992 and 2001, and share of the vote in 1997, with the corresponding figures for the previous election as controls. ${ }^{7}$ The data were analysed using stepwise multiple regression and, for each party at each election, with central involvement and membership being the key predictor variables. It is worth noting that these are stiff tests of the impact of the two independent variables as the control variables alone produce very large r-squared figures. $^{8}$

\section{[Table 8 About Here]}

The variables reported in Table 8 are logarithms (as in Table 2) and, for clarity of presentation and ease of interpretation, only coefficients for the key variables that are included as significant in the final equation are shown. ${ }^{9}$ The results suggest, first, that despite the improvements achieved by the Conservatives in the central coordination of constituency campaigns, this does not appear to have led to any measurable electoral payoff. The only positive coefficient in the Conservative equations is for the size of constituency party membership in 1997. For Labour, on these figures, central involvement appears to have had no independent impact on party performance in 1992, but was significantly and positively related to performance in both 1997 and 2001. By way of contrast, whilst Labour membership levels were positively related in 1992, in 2001 the relationship is negative. Things are more straightforward in the case of the Liberal Democrats. Somewhat 
paradoxically given the relatively small input of party headquarters to constituency campaigns, the central involvement index is related to party performance in both 1997 and 2001. On the other hand, membership impacts on performance in all three elections. However, whilst membership still had a greater impact than centralisation in 1997 , by 2001 , the impact of the latter had become more important.

\section{Conclusion}

It must be stressed again that the index of central involvement that we have used here cannot entirely capture all the features of increased central influence that we have described elsewhere using qualitative analysis (Denver et al, 2003). Nonetheless, it is useful and tends to corroborate the argument that in all three parties the influence of national officials over local campaigning has increased. The analysis of the impact of central involvement on electoral outcomes broadly confirms previous analyses of the impact of campaign intensity more generally. In spite of the considerable efforts made by Conservative Central Office in 1997 and 2001 these bore little fruit. This may reflect the relative autonomy and independence of Conservative Associations, which tend to be resistant to what may be seen as central 'interference'. On the other hand, in both 1997 and 2001 central involvement does appear to have had a significant impact on both Labour and Liberal Democrat performance. Assessing the results for party membership is a little more difficult but in the case of the Liberal Democrats things seem clear enough. The party has done well where it has built up strong local membership. It is not surprising, then that having controlled for previous performance, region and incumbency, there is a fairly strong relationship between size of membership and Liberal Democrat 
performance at each election, although by 2001 the impact of central influence had become greater.

The figures for Labour are more puzzling. Given the considerable effort that the party has put into developing centralised co-ordination of the constituency effort in key seats, we would expect to find - and do - significant relationships between the party's performance and the index of central involvement. The negative relationship between membership and performance in 2001 remains something of a mystery, however. As we have seen, the negative effect remains, even when we control for previous performance, region and incumbency. It is the case that in 2001 Labour did least well in its safest seats, and these in general are where it has its highest membership levels. This may have resulted from confidence in these areas that the election was going to be won easily or from the fact that little campaign effort was made in safe seats. Perhaps it may also reflect some disillusion with the government among activists in Labour heartlands. Whatever the reason, this result certainly casts doubts on Seyd \& Whiteley's view that party membership is the key to successful local campaigns. To be sure, Seyd \& Whiteley are correct in asserting that active members are more significant with regard to electoral payoffs than non-active ones. However, their assertion that large numbers of moderately active members will deliver as many electoral benefits as a small number of very active one seems contestable on the basis of these findings. Instead, they reinforce the view expressed elsewhere (Denver \& Hands, 2004) that, certainly in the case of the Labour party, the crucial factor leading to more effective local campaigning has been the role played by the party's central organisation in encouraging and helping to modernise campaigning in the key constituencies. 
Table 1

Correlations Between Full Campaign Index, Central Involvement Indexes and Membership Levels

$\begin{array}{lcccl} & \begin{array}{c}\text { Central Inv. } \\ \text { Index (Old) }\end{array} & \begin{array}{c}\text { Central Inv. } \\ \text { Index (New) }\end{array} & \begin{array}{c}\text { Number of } \\ \text { Members }\end{array} & \text { (Ns) } \\ \text { Con Campaign Index 1992 } & 0.144 * & \text { n/a } & 0.517 * * & (218 / 198) \\ \text { Con Campaign Index 1997 } & 0.161 * * & 0.190 * * & 0.521 * * & (364 / 338) \\ \text { Con Campaign Index 2001 } & 0.361 * * & 0.435 * * & 0.571 * * & (249 / 228) \\ & & & & \\ \text { Lab Campaign Index 1992 } & 0.315 * * & \text { n/a } & 0.591 * * & (294 / 281) \\ \text { Lab Campaign Index 1997 } & 0.418 * * & 0.538 * * & 0.401 * * & (386 / 372) \\ \text { Lab Campaign Index 2001 } & 0.363 * * & 0.521 * * & 0.256 * * & (300 / 287) \\ & & & & \\ \text { Lib Dem Campaign Index 1992 } & 0.243 * * & \text { n/a } & 0.745 * * & (313 / 307) \\ \text { Lib Dem Campaign Index 1997 } & 0.375 * * & 0.477 * * & 0.841 * * & (344 / 332) \\ \text { Lib Dem Campaign Index 2001 } & 0.290 * * & 0.393 * * & 0.787 * * & (294 / 282)\end{array}$

Notes $* *=p<0.01 ; *=p<0.05$. The two Ns shown refer to the coefficients involving the indices on the one hand and party membership on the other. 


\section{Table 2}

\section{Impact on Overall Campaign Intensity}

Con 1992

Con 1997

Con 2001

Lab 1992

Lab 1997

Lab 2001

Lib Dem 1992

Lib Dem 1997

Lib Dem 2001

$\begin{array}{rccc}\text { Central Inv. } & \text { Membership } & \text { Adjusted } \mathrm{R}^{2} & (\mathrm{~N}) \\ 9.072 & 15.097 & 0.489 & (198) \\ 16.166 & 14.462 & 0.515 & (338) \\ 29.905 & 16.289 & 0.623 & (228) \\ & & & \\ 15.063 & 33.829 & 0.368 & (281) \\ 32.113 & 30.773 & 0.335 & (372) \\ 41.033 & 23.444 & 0.379 & (287) \\ & & & \\ 10.835 & 20.764 & 0.558 & (306) \\ 13.467 & 23.275 & 0.670 & (331) \\ 15.684 & 22.507 & 0.582 & (282)\end{array}$

Notes: The variables for central involvement and membership are logarithms. All coefficients are significant at the $p<0.01$ level. The 'new' Central Involvement index is used for 2001 and 1997 and the 'old' index for 1992 
Table 3

Variations in the Extent of Central Involvement 1992-2001

\begin{tabular}{lrrr} 
& \multicolumn{1}{c}{ Conservative } & Labour & Liberal Democrat \\
$\begin{array}{l}\text { Old Index (Std Dev) } \\
1992\end{array}$ & & \\
$100(35.0)$ & $108(29.5)$ & $86(29.3)$ \\
1997 & $102(33.7)$ & $107(32.5)$ & $87(28.9)$ \\
2001 & $112(32.7)$ & $108(33.1)$ & $91(31.5)$ \\
New Index (Std Dev) & & & \\
1997 & $99(31.7)$ & $106(35.5)$ & $86(27.8)$ \\
2001 & $110(31.3)$ & $109(34.7)$ & $90(25.2)$
\end{tabular}




\section{Table 4 Central Involvement by Seat Status}

Conservatives

Held Not Target Target Not Held Not Target

(Ns)

1992 Old Index

9
$(131 / 32 / 55)$
95

112

97

1997 Old Index

$(164 / 54 / 146)$

2001 Old Index

109

127

101

1997 New Index

92

$(164 / 54 / 146)$

105

129

105

$(93 / 74 / 82)$

2001 New Index

125

98

132

103

$(93 / 74 / 82)$

Labour

1992 Old Index

101

121

103

1997 Old Index

99

149

100

(121/59/206)

2001 Old Index

101

129

99

$(113 / 74 / 113)$

1997 New Index

95

$121 / 59 / 206)$

2001 New Index

101

(113/74/113)

$160 \quad 97$

$137 \quad 98$

Liberal Democrats 1992 Old Index 1997 Old Index

$\begin{array}{rrrl}\text { N/A } & 92 & 85 & (-/ 22 / 291) \\ \text { N/A } & 126 & 84 & (-/ 23 / 322) \\ 124 & 113 & 90 & (4 / 19 / 271) \\ \text { N/A } & 126 & 83 & (-/ 23 / 322) \\ 120 & 114 & 86 & (4 / 19 / 271)\end{array}$

1997 New Index 120

114

$(4 / 19 / 271)$

Notes: The Ns shown are for each column. There were too few Liberal Democrat seats held but not targeted in 1992 and 1997 for separate analysis. 
Table 5 Party Members (mean) by Seat Status

Held Not Target Target Not Held Not Target (Ns)

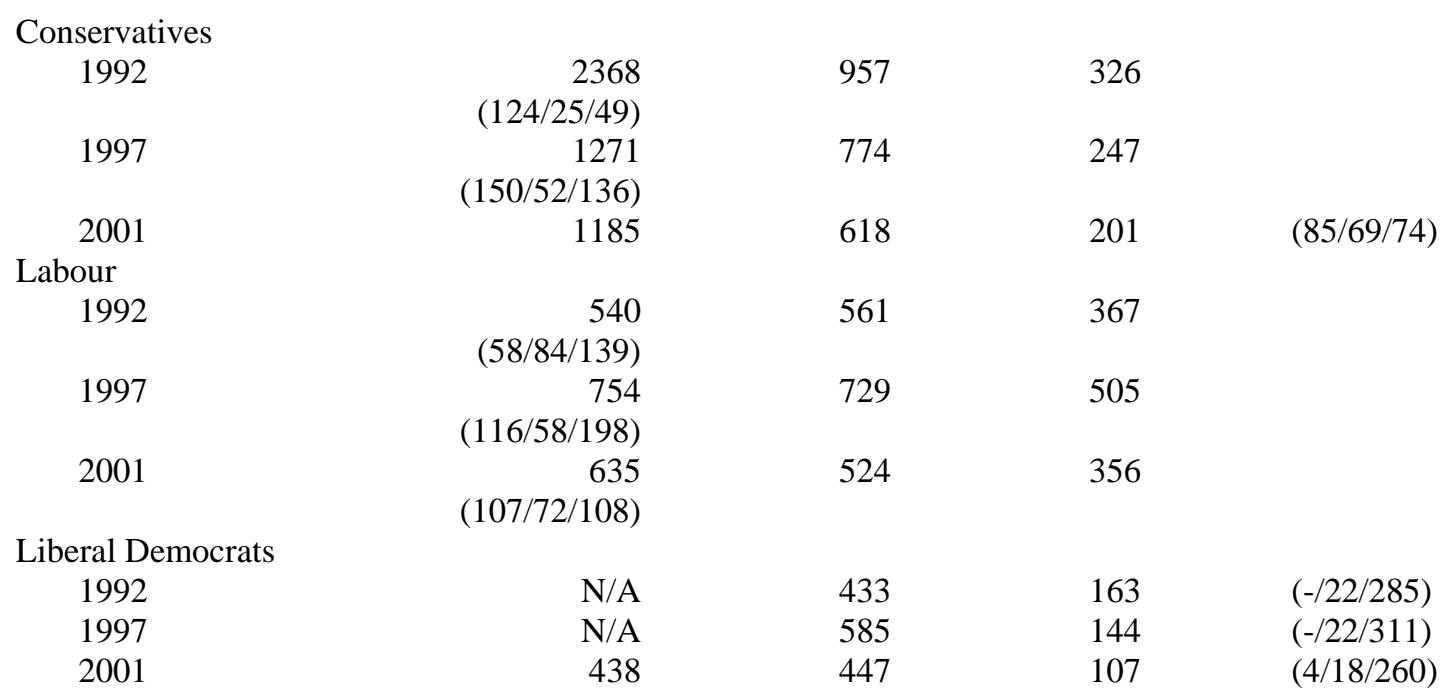

Notes: The Ns shown are for each column. There were too few Liberal Democrat seats held but not targeted in 1992 and 1997 for separate analysis. 


\section{Table 6}

The Electoral Impact of Central Involvement and Number of Party Members (Bivariate Correlations)

$\begin{array}{lccc} & \begin{array}{c}\text { Change in } \\ \text { Share of the } \\ \text { Vote }\end{array} & \begin{array}{c}\text { Change in } \\ \text { Share of the } \\ \text { Electorate }\end{array} & (\mathrm{N}) \\ \text { Conservative } & -0.069 & -0.073 & (218) \\ \text { 1992 Old Index } & 0.008 & \mathrm{x} & (364) \\ \text { 1997 New Index } & -0.090 & -0.063 & (249) \\ \text { 2001 New Index } & -0.193^{* *} & 0.105 & (198) \\ \text { Members 1992 } & -0.138^{*} & \mathrm{x} & (338) \\ \text { Members 1997 } & 0.120 & -0.165^{*} & (228) \\ \text { Members 2001 } & & & \\ \text { Labour } & 0.172^{* *} & 0.183^{* *} & (294) \\ \text { 1992 Old Index } & 0.203^{* *} & \mathrm{x} & (386) \\ \text { 1997 New Index } & 0.102 & -0.032 & (300) \\ \text { 2001 New Index } & 0.257^{* *} & 0.209^{* *} & (281) \\ \text { Members 1992 } & 0.131^{*} & \mathrm{x} & (372) \\ \text { Members 1997 } & -0.308^{* *} & -0.316^{* *} & (287) \\ \text { Members 2001 } & & & \\ \text { Liberal Democrats } & 0.149 & 0.129 & (313) \\ \text { 1992 Old Index } & 0.219^{* *} & \mathrm{x} & (345) \\ \text { 1997 New Index } & 0.127^{*} & 0.031 & (294) \\ \text { 2001 New Index } & 0.390^{* *} & 0.424^{* *} & (307) \\ \text { Members 1992 } & 0.406^{* *} & \mathrm{x} & (333) \\ \text { Members 1997 } & -0.047 & -0.278^{* *} & (282) \\ \text { Members 2001 } & & & \end{array}$

Notes: $\mathrm{x}=$ not available. $* *=\mathrm{p}<0.01, *=\mathrm{p}<0.05$. Changes in constituency boundaries mean that changes in electorate share cannot be calculated for 1997. 


\section{Table 7}

\section{The Electoral Impact of Central Involvement and Number of Party Members}

(Partial Correlations)

\section{Conservatives 1992 Old Index 1997 New Index 2001 New Index \\ Members 1992 \\ Members 1997 \\ Members 2001}

Labour

$$
\begin{gathered}
\text { Share of the } \\
\text { Vote }
\end{gathered}
$$

$-0.080$

$-0.057$

$-0.101$

$-0.163 *$

$0.232 * *$

0.054
Share of the Electorate

$-0.066$

$\mathrm{X}$

$-0.029$

$-0.134$

$\mathrm{X}$

$0.140^{*}$

$0.181^{* *}$

$\mathrm{X}$

$0.188 * *$

$0.178 * *$

$\mathrm{X}$

$-0.127 *$

0.079

$\mathrm{X}$

$0.185 * *$

$0.539 * *$

$\mathrm{X}$

$0.281 * *$
(N)

Notes: $\mathrm{x}=$ not available. ${ }^{*}=\mathrm{p}<0.01, *=\mathrm{p}<0.05$. Changes in constituency boundaries mean that changes in electorate share cannot be calculated for 1997. 


\section{Table 8}

The Electoral Impact of Central Involvement \& Numbers of Party Members (Multiple Regression Analysis)

$$
\begin{aligned}
& \text { Central Inv. } \\
& \text { Index Members }
\end{aligned}
$$

\section{2 \\ 1997 \\ 2001 \\ Conservatives}

$\mathrm{X}$
$\mathrm{X}$
$\mathrm{X}$

0.678

$\mathrm{X}$ X

Labour

1992

1997

$\mathrm{x}$

0.924

1.771

0.988

$\mathrm{x}$

2001

Liberal Democrats

1992

1997

2001

$\begin{array}{ll}\mathrm{X} & 2.037 \\ 1.588 & 1.774 \\ 1.039 & 0.684\end{array}$

Note: The variables for central involvement and membership are logarithms. $\mathrm{x}=$ Not significant. Minimum $\mathrm{N}$ as per Table 2. 


\section{Notes}

1. The surveys referred to in the paper were conducted in connection with ESRC-supported studies of constituency campaigning (grant reference numbers Y304 253004 (1992); R000222027 (1997) and R000239396 (2001)).

2. The variables included in the calculation of the indices measuring central involvement are as follows:

\section{'Old' Index}

- Amount of National contact before campaign (Hardly Ever, Occasionally, Once a Month, Once a Week)

- Amount of Regional contact before campaign (Hardly Ever, Occasionally, Once a Month, Once a Week)

- Amount of National contact during campaign (Hardly Ever, Once a Week, Every Day)

- Amount of Regional contact during campaign (Hardly Ever, Once a Week, Every Day)

- Whether used election software supplied by party headquarters (Yes/No)

- Whether special organiser appointed from centre (Yes/No)

'New' Index (1997 and 2001)

- Amount of National contact before campaign (Hardly Ever, Occasionally, Once a Month, Once a Week)

- Amount of Regional contact before campaign (Hardly Ever, Occasionally, Once a Month, Once a Week)

- Amount of National contact during campaign (Hardly Ever, Once a Week, Every Day)

- Amount of Regional contact during campaign (Hardly Ever, Once a Week, Every Day)

- Whether used election software supplied by party headquarters (Yes/No)

- Length of time special organiser appointed before election (Just Before the Election, Within the Last 6 Months, Within the Last Year, Over a Year Ago)

- Whether there was telephone canvassing from outside constituency (1997) (Yes/No)

- Whether there was outside telephone canvassing before the campaign (2001) ( Yes/No)

- Whether there was outside telephone canvassing during the campaign (2001) (Yes/No)

3. This is preferable to using a simple additive scale, since such scales treat all components equally in the calculation of the index.

4. This adjustment involves multiplying the factor score by 33.3 and then adding 100 .

5. The use of a lagged variable creates a dynamic specification of the model, which controls for the effects of the independent variables at the previous election. See, for example Whiteley \& Seyd, 1998, p.123. 
6. Region was analysed by a series of dummy variables for each of the standard regions in England with the West Midlands omitted as the comparator. Incumbency was also measured as a dummy variable.

7. Although the data are pooled to produce comparable centralisation index scores, it is necessary to run the models on an 'election by election' basis, rather that using interaction terms, as the dependent variable for 1997 (share of vote) differs from that of 1992 and 2001 (share of the electorate) because of boundary changes.

8. The Adjusted $r^{2}$ figures for equations predicting each party's vote/electorate share in each election on the basis of share in the previous election, region and incumbency are as follows:

$\begin{array}{lccc} & 1992 & 1997 & 2001 \\ \text { Conservative } & 0.966 & 0.951 & 0.943 \\ \text { Labour } & 0.943 & 0.943 & 0.924 \\ \text { Liberal Democrats } & 0.836 & 0.866 & 0.882\end{array}$

9. Full tables containing all variables are available from the authors on request. 


\section{References}

Crotty, W.D., 1971. Party Effort and Its Impact on the Vote. American Political Science Review. 65 (2), 439-50.

Denver, D. and Hands, G., 1997. Modern Constituency Electioneering. Frank Cass, London.

Denver, D. and Hands, G., 1998. Constituency Campaigning in the 1997 General Election: Party Effort and Electoral Effect. In: Crewe, I., Gosschalk, B., Bartle, J. (Eds) Why Labour Won the General Election of 1997. Frank Cass, London, pp. 75-92,

Denver, D. and Hands, G., 2004. Labour's Targeted Constituency Campaigning: Nationally Directed or Locally Produced? Electoral Studies. 23(4),709-26.

Denver, D., Hands, G., Fisher, J. and MacAllister, I., 2002. The Impact of Constituency Campaigning in the 2001 General Election. British Elections and Parties Review. 12, 80-94.

Denver, D., Hands, G., Fisher, J. and MacAllister, I., 2003. Constituency Campaigning in Britain 1992-2001: Centralisation and Modernisation. Party Politics. 9 (5), 541-59.

Denver, D., Hands, G. and Henig, S., 1998. Triumph of Targeting: Constituency Campaigning in the 1997 Election. British Elections and Parties Review. 8, 17190.

Fisher, J., 2000. Small Kingdoms and Crumbling Organisations: Examining the Variation in Constituency Party Membership and Resources. British Elections \& Parties Review. 10, 133-50.

Fisher, J., Denver, D., and Hands, G., 2006. Party Membership and Campaign Activity in Britain: The Impact of Electoral Performance. Party Politics. 12, XXX-XXX 
Jacobson, G.C., 1980. Money in Congressional Elections. New Haven, CT, Yale University Press.

Jacobson, G.C., 1990. The Effects of Campaign Spending in House Elections: New Evidence for Old Arguments. American Journal of Political Science. 34, 334-62.

Pattie, C. J., Johnston, R. J. and Fieldhouse, E. A., 1995. Winning the Local Vote: The Effectiveness of Constituency Campaign Spending in Great Britain, 19831992. American Political Science Review. 89 (4), 969-83.

Whiteley, P. and Seyd, P., 1994. Local Party Campaigning and Voting Behaviour in Britain. Journal of Politics. 56, 242-51.

Whiteley, P and Seyd, P., 1998. The Dynamics of Party Activism in Britain. British Journal of Political Science. 28 (1), 113-137

Whiteley, P. and Seyd, P., 2003. How to win a landslide by really trying: the effects of local campaigning on voting in the 1997 British general election. Electoral Studies. 22, 301-24. 